Physical Disabilities: Education and Related Services, 2014, 33(1), 39-52. doi: 10.14434/pders.v33i1.4969

(C) Division for Physical, Health and Multiple Disabilities

ISSN: 2372-451X

http://scholarworks.iu.edu/journals/index.php/pders/index

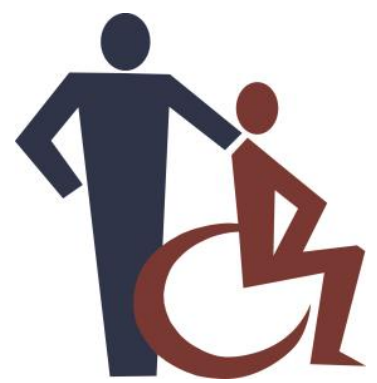

Article

\title{
DEVELOPING TRAINING PROGRAMS TO SAVE LIVES: SERVING STUDENTS WITH COMPLEX OR EMERGENCY HEALTHCARE NEEDS
}

\section{Annmarie Urso}

State University of New York College at Geneseo

Michael Rozalski

Binghamton University

\begin{abstract}
The number of students with special health care needs (SHCN; McPherson, Arango \& Fox, 1998) and the frequency of life-threatening health emergencies in schools (e.g., asthma, diabetes, severe allergic reactions, cardiac arrest, seizure disorders), continues to increase. It has become increasingly important for teachers to be trained in cardiopulmonary resuscitation (CPR) and use of automated external defibrillators (AED) in response to the growing number of students with SHCN in school settings and to assist life-threatening emergencies as they arise on school campuses. The purpose of this article is to describe a collaborative project that trained 38 preservice teachers to use CPR and AED in emergency situations. An established long-term goal of the project was to create a sustainable delivery model of three faculty members certified to train all preservice teacher candidates to competently provide first aid, perform CPR, and use an AED, while taking coursework and learning about support services for students with SHCN.
\end{abstract}

Keywords: medically fragile; $C P R ; A E D$ 


\section{Introduction}

Since the Individuals with Disabilities Education Act (IDEA; Public Law 101-476) was reauthorized in 1990, special education decision-making teams have been required to discuss the least restrictive environment in a different way. Since the inclusion of students in general education environments has become the clear preference for the first time, the practice of inclusion has increased. As a result, the number of students with disabilities served in community schools across the nation, including those who have complex health care needs, has increased. Prior to IDEA 1990, students who had serious or potential life-threatening health conditions were most often cared for in hospitals or in specialized schools designed to handle both their educational and complex medical needs (McPherson et al., 1998; van Dyck, Kogan, McPherson, Weissman, \& Newacheck, 2004). The trend toward deinstitutionalization, in combination with advances in medical technology and the call for inclusion by IDEA in 1990 (and subsequent reauthorizations in1997 and 2004), has resulted in more students with special health care needs (SHCN) being educated in their home school districts (American Federation of Teachers [AFT], 2009), despite the expenses (Buescher, Whitmire, Brunssen, \& Kluttz-Hile, 2006). The increase in the numbers of students with SHCN in public school settings, as well as the increase in emergency situations that lead to sudden cardiac arrest (SCA) of otherwise healthy individuals on school campuses, has led to specific legislation in 17 states to re-examine the role of school professionals in providing emergency care, and their obligation, both legal and ethical, to be trained to administer CPR and use an AED (National Conference of State Legislatures, 2013).

According to the American Heart Association (AHA), SCA is the leading cause of death in young athletes and Americans (2010a). SCA is caused by abnormal heart rhythm, or arrhythmias, which may result in the heart no longer pumping blood to the body. If this happens, for example during vigorous exercise, the child or young adult may experience ventricular fibrillation and subsequent cardiac arrest. There are several etiologies which could result in SCA including disease (e.g., cardiomyopathy), an inherited or congenital heart defect (that may or may not have been corrected by surgery), a cardiac condition that leads to inflammation of the heart, or a sharp blow to the chest that causes the heart to go into an irregular heart rhythm (Hazinski et al., 2004; National Institute of Health, 2011b). SCA differs from a heart attack, which occurs when the flow of oxygenated blood becomes blocked in a section of the heart (e.g., as a result of years of plaque build-up in someone with coronary heart disease; NIH, 2011a).

The American Association of School Administrators indicated that 7,000 to 10,000 young people die from SCA each year (Bingham, 2009; Sudden Cardiac Arrest Foundation, 2009). The results of a study on SCA in high school and college athletic programs from 2000-2006 found that students who experienced SCA had an $11 \%$ chance of survival (Sudden Cardiac Arrest Foundation, 2009). However, young athletes are not the only population at risk for SCA in the school setting.

In a 16-year study, Lotfi et al. (2007) classified by setting all incidents of SCA in King County and the city of Seattle in Washington state. During that time period, 3,773 cardiac arrests occurred in public locations and 97 (2.6\% of all public cardiac arrests) took place in schools. Of those 97, twelve were among students, 33 among faculty and staff, and 45 among adults not employed in the school (Lotfi et al., 2007). Upon examining the identified cause of cardiac arrest 
in eight students aged 3 to 18 years, Lotfi et al. found that four had a prior history of developmental disability or clinical cardiopulmonary disease and that the greatest population of pediatric cardiac arrests occurred in the school setting versus in hospitals or at home.

Immediate bystander CPR and early defibrillation are needed to treat SCAs that occur in public locations (Hazinski et al., 2004; Kamarainen, 2010, Lotfi et al., 2007). In places where an AED is present along with trained users, survival rates increase, and when CPR is performed immediately with effective delivery of chest compressions, CPR can double or triple a victim's chance for survival (AHA, 2010a). A recent study by the AHA (2010a) on SCA demonstrated that approximately two-thirds of the annual 300,000 fatalities resulting from SCA in the United States did not involve early CPR. However, the use of CPR and AED can improve outcomes for persons who experience SCA. An example to illustrate the positive impact of CPR/AED use occurred in 2010 at a school district near the college where this training program was implemented; in this case two staff members used early CPR and an AED to save a 14-year old girl who had a heart attack at an indoor track practice (Wordingham, 2010). Similar stories of student-athletes who had SCA and were saved by CPR/AED have also been documented (The Sudden Cardiac Arrest Foundation, 2009). The AHA and the National Association of Emergency Medical Service Physicians stated that AEDs may be used in combination with CPR in children as young as 12 months (AHA, 2010b; Hazinski et al., 2004). Additionally, other medical professionals substantiate the need for AEDs in school settings based on the high percentage of cardiac arrests that occur in students with SHCN in the school setting (Lotfi et al., 2007).

The integral role of teachers and paraprofessionals, who often find themselves responding to, and caring for, students with complex or emergency health care needs, led to the development of a self-sustaining training program for preservice teacher candidates at the State University of New York College at Geneseo. The training included first aid, CPR and AED use, and awareness of specific issues students with SHCN may present. The following information describes the development of the project and suggested sources of funding and collaborations.

\section{Program Development}

Project development took more than three years from conception to implementation. Development began with a thorough assessment of needs for school nurses and preservice teachers (including a literature review), creation of partnerships and grant funding, and training or re-training of key project personnel. A pilot course with CPR and AED training only was offered and then redesigned into a full course that also addressed service provision for students with SHCN.

\section{Assessment of Needs}

To determine the need for the project, we surveyed both local school nurses and candidates in a preservice teacher preparation program and completed a thorough review of the literature. Each step of the process is briefly described in this section.

Survey of school nurses. To assess the need for this project, we selected and interviewed a convenience sample of six school nurses from local school districts that frequently hosted the 
preservice teacher candidates for practicum and student teaching placements. The questions were in a yes/no format that invited follow-up questioning by the interviewer as well as opportunity for additional explanatory comments by the nurses. Each semi-formal interview included the following questions and responses to each question (see Table 1).

Table 1

Number of Nurses Responding to Each Yes/No Question

\begin{tabular}{|c|c|c|c|}
\hline \multicolumn{2}{|c|}{ Question } & \multirow{2}{*}{$\begin{array}{c}\text { Yes } \\
1\end{array}$} & \multirow{2}{*}{$\begin{array}{r}\text { No } \\
5\end{array}$} \\
\hline 1. & $\begin{array}{l}\text { Have you had an occasion to use CPR or an AED } \\
\text { on a student in your school? }\end{array}$ & & \\
\hline 2. & $\begin{array}{l}\text { Do you know if anyone else has used CPR or AED } \\
\text { on a student? }\end{array}$ & 1 & 5 \\
\hline 3. & $\begin{array}{l}\text { Does your school have any students that require an } \\
\text { AED be present and teachers and/or service } \\
\text { providers who work specifically with these } \\
\text { students be trained in CPR and AED use? }\end{array}$ & 6 & 0 \\
\hline 4. & $\begin{array}{l}\text { Has CPR or an AED been used on school property } \\
\text { to respond to a medical emergency for a } \\
\text { community member or school personnel? }\end{array}$ & 2 & 4 \\
\hline 5. & $\begin{array}{l}\text { Since New York State only requires school health } \\
\text { personnel and athletic coaches to have CPR and } \\
\text { AED training, in your professional opinion, would } \\
\text { it be helpful to have more school personnel trained } \\
\text { in CPR and AED use? }\end{array}$ & 6 & 0 \\
\hline
\end{tabular}

All six school nurses reported that during the past 10 years there was an increase in the number of students with SHCN who's Individualized Health Plans (IHPs) required teachers and other school personnel to be able to administer CPR and use AEDs. They also noted, as research suggests (Cave et al., 2011; Drezner et al., 2007; Lotfi et al., 2007), training teachers in CPR and AED use benefits entire communities since as many as $20 \%$ of a community's population are on school grounds daily for athletic and other extracurricular events. As two school nurses noted, "As school nurses, we plan for emergencies, but they don't always tend to happen when we are on site," (R. Kwiecien, RN, personal communication, May 20, 2010) and "It would be good to know that student teachers are trained in CPR/AED use...knowing we can count on that additional person would be valuable to our emergency management plan" (C. Snider, RN, personal communication, May 20, 2010).

As a result of the increasing numbers of students in public schools with SHCN and those who have serious health issues that are potentially life threatening, there is an expectation, or in some states or situations a requirement, for educators, paraprofessionals, and support staff to perform skills and duties that in the past have been reserved solely for the school nurse and other health care professionals (AFT, 2009; National Conference of State Legislatures, 2013). 
Survey of preservice teacher candidates. In March 2010, we surveyed 50 preservice teacher candidates in three different teacher preparation programs: special education $\left(1-6^{\text {th }}\right.$ grade), early childhood education (P-2 ${ }^{\text {nd }}$ grade), and childhood education $\left(1-6^{\text {th }}\right.$ grade). Candidates were asked five questions: (a) have you ever taken a CPR/AED or first aid course; (b) are you currently certified in either CPR/AED or use of first aid; (c) would you be willing to take a course on CPR/AED, first aid and students with SHCN offered by our School of Education; (d) would you be willing to pay under $\$ 50$ for course materials for that course; and (e) why might persons (students, staff, community members) in school settings need to be prepared to administer CPR/AED, first aid, or be aware of the specific needs of students with SHCN? After reviewing the data collected from the surveys, we discovered five of the surveyed candidates were already certified in CPR/AED and all five were employed during the summer as lifeguards. To fulfill summer job requirements, five other preservice teacher candidates had already signed up for an off-campus CPR/AED course; none of these five had been previously trained. The remaining 40 preservice teacher candidates indicated that they would be willing to attend CPR/AED and first aid training offered by School of Education faculty members, as long as it did not interfere with their class/work schedules and did not cost more than $\$ 50$ for the course materials. We also determined from the candidate surveys that preservice teachers lacked training in, and understanding of, complex health conditions experienced by students with IHPs. Based on this information from the surveys and additional conversations with the school nurses, we decided to include this topic in our literature review for the purposes of course development.

Review of literature. Using Science Direct, ERIC, Scopus, and Academic Search Premier, a literature review of students with complex or emergency medical needs (e.g., special medical needs, medically fragile students, medical emergencies in schools), SCA, and the use of CPR/AEDs in schools was conducted to determine the incidence of SCA and the impact of $\mathrm{CPR} / \mathrm{AED}$ use on survival rates. Additionally, a review of literature on recommendations and requirements by state departments of education and professional member organizations for teachers and school nurses was conducted to determine legal and ethical responsibilities of teachers and other school staff. The review of literature was completed because both teachers and other school staff routinely work with students with SHCN and may respond to medical emergencies involving SCA in school settings.

\section{Developing Partnerships and Funding Sources}

The major funding for the purchase of the training equipment for this project came from the National Education Association Foundation (NEAF) and included:

- Two AHA instructor manuals and training DVDs;

- Fifty student manuals;

- Six infant and 12 child/adult CPR manikins with replaceable airway lungs;

- One hundred masks with one-way valves and 400 face shields;

- Twelve AED trainers, batteries, and 10 replacement pads;

- 24 first aid training supply kits (e.g., epi-pen trainer, bandages); and

- Miscellaneous equipment (e.g., stop watches, disinfectant for manikins).

At a cost of approximately \$1,200 each, functioning AEDs are expensive. Many school districts report that the AEDs in their schools were either funded by or donated by local civic groups and recent legislation supports the costs of funding in several states (National Conference of State 
Legislatures, 2013; The Sudden Cardiac Arrest Foundation, 2009). Local sources worth investigating for both start up and sustainable funding include: (a) community health organizations; (b) community services boards; (c) local, county, regional, and state-wide nonprofit foundations and community focused organizations (e.g., private foundations, hospital auxiliaries, faith-based groups); (d) community-minded businesses that provide grants for local service projects (e.g., Albertsons, Wegmans - both regional/national grocery store chains); (e) state-wide and local chapters of professional service organizations (e.g., Rotary, Lions Club, Kiwanis); and (f) clearinghouses for grant and fundraising sources for nonprofit organizations and schools.

\section{Training Faculty}

Two of the participating faculty members had previously been certified in New York as Emergency Medical Technicians. With the assistance of the local Emergency Medical Training Center, these two faculty members and an additional faculty member became certified instructors for the American Heart Association in the use of CPR and AEDs. The training of three faculty members enabled our program to provide training in first aid, CPR and AED use, and in supporting students with SHCN (e.g., students whose medical conditions require them to carry AEDs for cardiac emergencies or epinephrine pens for allergies, students who are oxygen or ventilator dependent). We also developed a more comprehensive curriculum for working with students with SHCN, which was subsequently offered as an experimental course. The long-term goal of this project was to develop the knowledge and skills necessary to develop a comprehensive curriculum to prepare other faculty members and preservice teacher candidates to support students with SHCN in inclusive public school settings.

\section{Pilot CPR/AED Course}

With the very generous assistance and equipment loans from the local Emergency Medical Services agency and the local fire department, we conducted a pilot training program on campus during the spring of 2010, acknowledging the pilot program as a one-time, unsustainable opportunity. Without our own dedicated training equipment, School of Education and college approved course content, and a secured course rotation schedule led by trained School of Education faculty, we could not offer the course with any consistency. We could offer the course to only 24 preservice teacher candidates during the pilot because of limited equipment and trainer availability (two manikins, two AED trainers and an instructor are needed for every six candidates seeking CPR/AED certification). Twenty-eight of the 40 preservice teacher candidates signed up; the remaining 12 indicated that they were still interested but could not attend the day/time scheduled. At the conclusion of the pilot program, we anonymously surveyed participants. On a scale of 1-4, 4 being strongly agree, all participants indicated that they strongly agreed that the course met their expectations (average 4.0) and they would recommend the course to others (average 4.0). The pilot program, only possible with the generous support from Livingston County and the Geneseo Fire Department, was well received by the students as indicated by their high rate of satisfaction with the course. 


\section{Developing the Full Course}

Although three faculty members had already received formal training in first aid and CPR/AED, further work with faculty from the School of Education, personnel from the local emergency medical services agency, and personnel from a local school were needed to develop a comprehensive curriculum on supporting students with specific medical conditions. To create a replicable experience for our preservice teacher education candidates, however, we understood that the curriculum needed to be formalized as a 3-credit course. This required the development of course objects to meet the needs of preservice teacher candidates in the introduction to teaching and supporting students with SHCN in the classroom.

Course objectives. As a registered teacher preparation program leading to initial generalist special education certification in the state of New York, we are mandated to provide training that meets the competencies - both state and professional association - for the type of certification our students earn. Our program has no state-mandated certification requirements in regards to specialty competencies for the preparation of teachers of students with physical and health disabilities. While the Council for Exceptional Children (CEC) does have professional standards for the preparation of teachers of students with physical and health disabilities, this course was not designed to meet the depth or breadth of the CECs initial standards specialty set for teachers of students with physical and health disabilities. The CEC initial standards do not require training in the use of CPR and AED. Our course was designed to address the needs of generalist special education teacher preparation programs in regards to students with SHCN in the classroom that may require CPR/AED.

Based on the first author's experience as a teacher of students with SHCN, the interviews with school nurses, and lessons learned from the literature, learner outcomes were developed for the course. Table 2 contains the outcomes, rationales, and examples of activities used to meet the outcomes.

CPR/AED and first aid coursework. In many ways, we did not recreate the wheel. The AHA has excellent training programs for first aid and CPR/AED and we purchased and used that curriculum (i.e., Heartsaver) and the related supplies (e.g., the CPR manikins and AED trainers). As trainers, the authors and other trained faculty members were able to effectively and efficiently train and certify all preservice teacher candidates during the course. We built in the required time to follow the AHA curriculum into the course and received a grant from the NEAF to purchase the CPR manikins, AED trainers, and related supplies (e.g., epinephrine pen trainers, personal protective gear). 
Table 2

\section{Learning Outcomes}

Upon successful completion of the course, the preservice teacher candidates will:

1. Define students with complex and emergency health care needs.

2. Demonstrate knowledge of life systems impacted in students with complex health care needs.

3. Discuss how the Centers for Disease Control (CDC) recommendations for working with students with complex health care needs can be implemented in classrooms and schools.

4. Identify special issues encountered by students with complex health care needs, their families, friends, care providers and schools.

5. Identify and understand the function of basic life support equipment that may be used with students with complex health care needs.
Rationale

Sample Activities
Identify common ailments, conditions and diseases that require significant medical support (AFT, 2009). Identify sudden cardiac arrest (SCA) and common signs.

Recognize the potential impact of complex health care needs on students' bodies (AFT, 2009; Delgado, 1999; Drezner et al., 2007).

Recognize that external supports are available to support successful integration efforts (AFT, 2009; CDC, 2009).

Recognize the potential impact of complex health care needs on students' families and support systems (AFT, 2009; Buescher et al., 2006).

Develop an appreciation for the complexity of the support equipment that students may require in schools (AFT, 2009; Hazinski et al., 2004).
Review and discuss print material, websites (e.g., CDC, NIH) and videos. Present specific issues per Learning Outcome \#12.

Review and discuss basic body systems. Present specific issues per Learning Outcome \#12.

Review and discuss CDC website and print material.

Presentation and discussion of movies and documentaries (e.g., Lorenzo's Oil, Life According to Sam) and readings. Present specific issues per Learning Outcome \#12.

Presentation of equipment (e.g., suction). Present specific issues per Learning Outcome \#12. 
6. Understand the responsibilities of teachers in the development and execution of the Individualized Health Care Plan.

7. Articulate the importance of being prepared for potential school emergencies.

8. Identify scene and personal safety issues that may prevent teachers or staff from responding safely.

9. Demonstrate knowledge of appropriate emergency response skills.

10. Demonstrate CPR, AED, and basic first aid skills, including response to choking.

11. Respond effectively to emergency scenarios and role-plays.

12. Develop professional development activities for other school professionals.
Appreciate the role which teachers can play when supporting students (Cave et al., specific issues per Learning Outcome \#12. 2011; Hazinski et al., 2004).

Identify why and how to prepare for common school emergencies (Delgado, 1999; Hazinski et al., 2004).

Ensure that preservice teacher candidates do not become part of the need for emergency services (Drezner et al., 2007).

Ensure that preservice teacher candidates have practiced skills from notification of emergency responders to first aid (Drezner et al, 2007; Hazinski et al., 2004).

Practice CPR/AED application and typical first responder activities, including assisting an infant, child or adult who is choking (AHA, 2010a; Cave et al., 2011; Delgado, 1999; Sudden Cardiac Arrest Foundation, 2009).

Ensure that preservice teacher candidates have exposure to a variety of potential real-life situations (Drezner et al., 2007; Hazinski et al., 2004).

Research and share resources about specific medical conditions (Urso \& Rozalski, 2011).
Develop and present sample IHP based on

Review, develop and present sample emergency response plans. Conduct "reviews" of possible hot spots (e.g., safety audits of school labs and on playgrounds).

Completed practical tests that required identification of issues related to scene safety.

Completed written and practical tests that required application of basic first aid skills.

\section{Completed AHA's Heartsaver CPR/AED} training for Adults/Children and Infants (with mask and choking) and First Aid training.

Using video vignettes of emergency situations, students discussed and acted out how to respond.

Developed in-class presentation and handouts about specific medical conditions that students with complex health care needs encounter. 


\section{First Year Impact}

During this project, three faculty members were trained/re-certified and 38 preservice teacher candidates were trained in AHA CPR/AED and first aid. In terms of P-12 students, the 38 preservice teacher candidates were in classrooms a total of 150 hours prior to their student teaching placements. Once student teaching, the preservice teacher candidates complete 12 weeks of daily contact with students in P-12 school buildings of varying sizes. We estimated in year one, based on average class sizes, 770 P-12 students were being served by our preservice teacher candidates certified in CPR, AED usage, and first aid.

\section{Value Added to Candidates Trained}

As a result of the program described in this paper, CPR/AED training was offered as part of a comprehensive, 3-credit course developed on teaching students with SHCN. The course provided AHA certification in HeartSaver CPR/AED. Additionally, coursework focused on individualized health plans (IHP), commonly used medical equipment, a survey of physical, medical and emergency conditions that lead to a student experiencing complex health or emergency care "status," and the roles of the educator in collaborating with families and medical professionals in regards to the education, health, and safety of students with complex health care needs.

This is an excerpt from a letter sent to the first author by a student who completed the course in 2011:

I was hired on the spot to be a teacher's aide this July for their summer program. The reason they [United Cerebral Palsy program] decided to hire me so quickly was because of the CPR/AED training, my knowledge of an IHP, and the fact that I took the medically fragile class. (K.M. Haig, personal communication, May 30, 2012)

\section{Implications for the Future}

Developing and offering this course had both local and more widespread implications. In this section, we discuss the implications for the course offering, a connection to the big picture of teacher preparation, and limitations.

\section{The Course}

By designing and offering the first course at SUNY Geneseo, we have made many adjustments to activities and readings to better meet preservice teacher candidates' needs and possible future experiences. The authors continue to develop a sustainable framework so that a future course offering for candidates is consistently available at Binghamton University. The need for replicating the course and continuing to improve the candidate experience is necessary. To this end, we are developing a course review and evaluation process that will allow us to revise the course to reflect the most update curriculum and information available and will create a common evaluation survey for participants so that we can share lessons learned across our campuses. 


\section{Big Picture}

Increases in students with SHCN being included in schools and well-publicized cases of SCA in young people have led to increased awareness for training in CPR/AED. With the advent of hands only CPR, and a variety of options for taking classes in CPR/AED, the AHA is reporting more individuals are being trained in CPR than ever before - over 12 million people are trained annually (American Heart Association, http://www.heart.org/HEARTORG/CPRAndECC/WhatisCPR/CPRFactsandStats/CPRStatistics_UCM 307542_Article.jsp, Cardiac Statistics, para 4).

To improve outcomes for SCA, training in CPR/AED is needed. There has been an increase in national legislative attention for training in CPR/AED to improve SCA outcomes with the introduction of the Josh Miller Helping Everyone Access Responsive Treatment in Schools (HEARTS) Act (H.R. 1311/S. 2106). Miller, an otherwise healthy 15 year-old, died of SCA during a football game. This bill would authorize the U.S. Secretary of Education to award grants to local educational agencies to buy AEDs and provide funds to train teachers and staff in using AEDs and CPR. The program's goal would be to treat heart-attack victims while waiting for emergency personnel to arrive. The legislation would require schools to provide $\$ 1$ of private funding for every $\$ 3$ of federal funding received through the program. The National Education Association (2012) and the American Heart Association/American Stroke Association (2012) strongly support the Josh Miller HEARTS Act, which, as of March 11, 2014, moved to the U. S. Senate Committee for consideration. This important piece of legislation would (a) authorize funding through the reauthorization of the Elementary and Secondary Act for schools to purchase AEDs, (b) require adequate training of teachers and staff in CPR/AED, and (c) encourage schools to create medical emergency response plans. Other key features of this legislation include:

- Purchase of AEDs: Local education agencies may apply for the purchase of AEDs for any public or private school in their jurisdiction. Priority is given to schools without access to an AED, schools with a large student and staff population, and schools without timely access to emergency care.

- Training: The bill requires that at least five adults in each school should be trained and certified in CPR and the use of an AED. Funding provided by the Josh Miller HEARTS Act may be used for training in addition to the purchase of an AED.

- Medical Emergency Response Plans: The legislation encourages schools to create medical emergency response plans and integrate the use of an AED into such plans. The bill also requires schools to notify local emergency services personnel of the placement of the AED in their school.

- Funding: The bill authorizes funding through 2017. The bill requires that the applicant provide $\$ 1$ of matching funding for every $\$ 3$ of federal funding (American Heart Association, 2010c)

\section{Limitations}

The project described here could not initially have been possible without tremendous support. The second author is a volunteer member of the local emergency medical services agency. 
Without this connection to the training supplies, resources, and the AHA curriculum, this program would not have been possible. Although we eventually procured grant support from the NEAF to purchase the resources needed, it is likely that replication for the reader would require a similar connection to either access these resources or procure grant support. Additionally, initially training allowed only a small cohort to receive the training. In the future, we would need to make this a required course for all preservice teacher candidates. A required course would significantly impact the number of teacher candidates who would have the specific knowledge of CPR/AED, first aid and serving students with SHCN.

\section{Conclusions}

Efforts to offer CPR/AED certification to preservice teacher candidates progresses toward sustainability, which means that no additional resources are required to offer the training. The atcapacity registrations of both the stand alone certification course and the general course with CPR/AED, first aid and issues related to students with SHCN embedded in the content, provided the preservice teacher candidate support needed to seek the placement of the general course in the rotation of elective courses offered at our university. The course has been and will continue to be offered once a year. The last few classes have operated at capacity.

It is our belief that training preservice teachers to respond to the cardiac needs of students with SHCN and students who experience SCA should be mandated by state licensing boards. States have very different requirements for health care professionals and athletic coaches than they do for teachers and staff; even among the regulations for health care professionals and athletic coaches there is great variation (c.f., National Association of State School Nurse Consultants, 2003; National Conference of State Legislatures, 2013). The provision of federal funding from proposed legislation, access to more flexible training programs, and access to funding sources to defray the cost of AEDs, is encouraging: schools will now have the opportunity to be prepared to assist students with SHCN, as well as students, staff, and community members who experience SCA on school campuses.

\section{References}

American Federation of Teachers. (2009). The medically fragile child: Caring for children with special healthcare needs in the school setting. Retrieved from http://www.aft.org/pdfs/healthcare/medicallyfragilechild0409.pdf

American Heart Association. (2010a). CPR statistics. Retrieved from http://www.heart.org/HEARTORG/CPRAndECC/WhatisCPR/CPRFactsandStats/CPRStatistics_UCM_307542_Article.jsp

American Heart Association. (2010b). Highlights of the 2010 American Heart Association guidelines for CPR and ECC. Retrieved from http://www.heart.org/HEARTORG/CPRAndECC/Science/Guidelines/GuidelinesHighlights_UCM_317219_SubHomePage.jsp 
American Heart Association. (2010c). More than 40 organizations issue call to action on sudden cardiac arrest. [Press Release]. Retrieved from http://newsroom.heart.org/news/1133

American Heart Association (2012). Sudden cardiac arrest: The Josh Miller HEARTS Act. $\underline{\text { Retrieved from }}$ http://www.heart.org/HEARTORG/Advocate/IssuesandCampaigns/AccesstoCare/Sudden -Cardiac-Arrest---Advocacy_UCM_312652_Article.jsp

Bingham, D. (2009). Shocking statistics. American School \& University. Retrieved from: http://asumag.com/security/life_safety/aed-school-university-use-200903

Buescher, P., Whitmire, J., Brunssen, S., \& Kluttz-Hile, C. (2006). Children who are medically fragile in North Carolina: Using Medicaid data to estimate prevalence and medical care costs in 2004. Maternal and Child Health Journal, 10(5), 461-466. http://dx.doi.org/10.1007/s10995-006-0081-3

Cave, D. M., Aufderheide, T. P., Beeson, J., Ellison, A., Gregory, A., Hazinski, M. F., . . . Schexnayder, S. M. (2011). Importance and implementation of training in cardiopulmonary resuscitation and automated external defibrillation in schools. Circulation, 123(6), 691-706. http://dx.doi.org/10.1161/CIR.0b013e31820b5328

Centers for Disease Control. (2009). Questions and answers about the CDC guidance for state and local public health officials and school administrators for school (K-12): Responses to influenza during the 2009-2010 school year. Retrieved from http://www.cdc.gov/h1n1flu/schools/toolkit/questions.htm

Delgado, E. (1999). Learning the ABC's can save a life. Why classroom teachers should be certified in CPR and pediatric first aid. Retrieved from ERIC database. (ED431759)

Drezner, J. A., Courson, R. W., Roberts, W. O., Mosesso, V. N., Link, M. S., \& Maron, B. J. (2007). Inter-Association task force recommendations on emergency preparedness and management of sudden cardiac arrest in high school and college athletic programs: A consensus statement. Heart Rhythm Journal, 4, 549-564. http://dx.doi.org/10.1016/j.hrthm.2007.02.019

Hazinski, M. F., Markenson, D., Neish, S., Gerardi, M., Hootman, J., Nichol, G., . . Smith, S. (2004). Response to cardiac arrest and selected life-threatening medical emergencies: The medical emergency response plan for schools - A statement for healthcare providers, policymakers, school administrators, and community leaders. Annuals of Emergency Medicine, 43(1), 83-99. http://dx.doi.org/10.1016/j.annemergmed.2003.11.001

Kamarainen, A. (2010). Out-of-hospital cardiac arrests in children. Journal of Emergencies, Trauma, and Shock, 3(3), 273-276. http://dx.doi.org/10.4103/0974-2700.66531

Individuals With Disabilities Education Act, 20 U.S.C. $§ 1400$ (2004). 
Lotfi, K., White, L., Rea, T., Cobb, L., Copass, M., Yin, L., ...Eisenberg, M. (2007). Health services and outcomes research: Cardiac arrest in schools. Circulation, 116, 1374-1379. http://dx.doi.org/10.1161/CIRCULATIONAHA.107.698282

McPherson, M., Arango, P., \& Fox, H. B. (1998). A new definition of children with special health care needs. Pediatrics, 102, 137-140. http://dx.doi.org/10.1542/peds.102.1.137

National Association of State School Nurse Consultants. (2003). The state responses on CPR certification and AED's in schools. Retrieved from http://www.shapeamerica.org/advocacy/positionstatements/sports/loader.cfm?csModule= security/getfile \&pageid $=4605$

National Conference of State Legislatures. (2013). State laws on cardiac arrest and defibrillators. Retrieved from http://www.ncsl.org/research/health/laws-on-cardiac-arrestand-defibrillators-aeds.aspx

National Education Association. (2012). NEA-supported bills on NCLB for the $112^{\text {th }}$ congress. Retrieved from http://www.nea.org/home/13274.htm

National Institute of Health, National Heart, Lung and Blood Institute. (2011a). What is a heart attack? Retrieved from http://www.nhlbi.nih.gov/health/health-topics/topics/heartattack/

National Institute of Health, National Heart, Lung and Blood Institute. (2011b). What is sudden cardiac arrest? Retrieved from http://www.nhlbi.nih.gov/health/healthtopics/topics/scda/

Sudden Cardiac Arrest Foundation. (2009). You can save a life at school. Wexford, PA: Author.

Urso, A. \& Rozalski, M. E. (2011, April). Developing training programs in CPR/AED: Saving lives, serving medically fragile children. Poster presented at the annual meeting of the Council for Exceptional Children, National Harbor, MD.

van Dyck, P. C., Kogan, M., McPherson, M., Weissman, G. R., \& Newacheck, P. W. (2004). Prevalence and characteristics of children with special health care needs. Archives of Pediatrics \& Adolescent Medicine, 158, 884-890. http://dx.doi.org/10.1001/archpedi.158.9.884

Wordingham, J. (2010, March 17). Gates Chili student's life saved by quick-thinking trainers. The GatesChiliPost.com. Retrieved from http://www.gateschilipost.com/latestnews/x1664763186/Gates-Chili-students-life-savedby-quick-thinking-trainers

Author note. This project was funded by a grant from the National Education Association Foundation Learning \& Leadership Grant LL29-24. The authors wish to acknowledge the Livingston County (New York) Emergency Medical Services and the Geneseo Fire Department (New York) for their support of the project. Correspondence concerning this article should be addressed to Annmarie Urso, Ella Cline Shear School of Education, SUNY Geneseo, Geneseo, NY 14454, e-mail: urso@geneseo.edu. 